\title{
Analysis of Treg/Th17 cells in patients with tongue squamous cell carcinoma
}

\author{
CHANGFU LIU ${ }^{1}$, ZHOU TONG ${ }^{1}$, JINGYU TAN ${ }^{2}$ and ZENGXI XIN ${ }^{3}$
}

Received January 15, 2019; Accepted June 27, 2019

DOI: $10.3892 /$ etm.2019.7814

\begin{abstract}
The aim of the present study was to analyze the percentage of regulatory T cells (Treg) and T helper cell 17 (Th17) cells in the peripheral blood of patients with tongue squamous cell carcinoma (TSCC) to provide novel insight into the development of immune-targeting therapies for TSCC. Peripheral blood samples were collected from 40 patients with TSCC then the peripheral blood mononuclear cells (PBMCs) and plasma were isolated for flow cytometry, cytometric bead array and reverse transcription-quantitative PCR. Results demonstrated that the percentage of cluster of differentiation (CD)4+ T cells in the peripheral blood of patients with TSCC decreased significantly compared with the control. However, the percentage of Treg and Th17 cells increased significantly compared with the control. The levels of interleukin (IL)-10 and IL-17a increased significantly in patients with TSCC. Expression of IL-10 and IL-17 in the advanced stages of cancer (stage III or IV) were significantly higher compared with the early stages (I and II). The mRNA expression levels of the transcription factors forkhead box protein 3 and RAR-related orphan receptor- $\gamma$ increased significantly with stage of cancer. The percentage of Treg cells and Th17 cells increased significantly in patients with TSCC suggesting that there was an imbalance between Treg and Th17 cells. In conclusion, altered Treg/Th17 balance in TSCC may promote the disease progression and these results provide a theoretical basis for the development of immunomodulators targeting Treg/Th17.
\end{abstract}

Correspondence to: Dr Zengxi Xin, Department of Prosthodontics, The Second Affiliated Hospital of Jinzhou Medical University, 49 Section 2 Shanghai Road, Jinzhou, Liaoning 121000, P.R. China E-mail: xinzengxi121@sina.com

Abbreviations: TSCC, tongue squamous cell carcinoma; Treg, regulatory $\mathrm{T}$ cells; Th17, $\mathrm{T}$ helper cell 17; TME, tumor microenvironment; TAM, tumor infiltrating lymphocyte; MDSC, myeloid-derived suppressor cells; PBMCs, peripheral blood mononuclear cells

Key words: TSCC, Treg, Th17, interlukin-10, interlukin-17

\section{Introduction}

Carcinoma of the tongue is the most common malignant tumor in the oral and maxillofacial region, of which tongue squamous cell carcinoma (TSCC) is the most prevalent, seriously affecting the patients' quality of life (1). The underlying mechanism of occurrence and development of TSCC has been a focus of oral and maxillofacial surgery; however, additional studies are required to understand the etiology to improve treatment and prognosis of TSCC (2).

The tumor microenvironment (TME) includes tumor cells and their surrounding cellular and non-cellular components. $\mathrm{T}$ cells, granulocytes and myeloid-derived suppressor cells (MDSC) all serve a role in the formation of the TME (2). In addition, non-immune cells, protein molecules, inflammatory cytokines and chemokines are also present in the TME (2-4). The TME makeup is dynamic with the nature of the matrix and cells present constantly changing. This results in a large number of immunosuppressive cells such as Treg, MDSC, tumor infiltrating lymphocyte and inflammatory molecules and mediators such as interleukin (IL)-6, IL-10 and transforming growth factor (TGF)- $\beta$ aggregating in the TME (5). The body mobilizes a wide array of immunosuppressive strategies to control and limit tumor development. In addition, cancer cells can activate various signaling factors through a series of pathways to avoid destruction resulting in immune escape (6-8).

Regulatory T cells (Treg) are a subset of immune cells with immunoregulatory effects. These cells primarily secrete IL-10 and TGF- $\beta$, which exhibit a strong immunosuppressive function and serve an important role in tumor immune escape (9). Thelper cell 17 (Th17) is another recently discovered subgroup of CD4+ T cells named due to their characteristic secretion of IL-17. Th17 cells exhibit a strong pro-inflammatory effect and participate in the development of many immune-associated diseases and tumors (10). Zhou et al (11), found that, B cells convert CD4+ CD25- T cells into Tregs in co-culture with TCSS cells and influence the prognosis of patients with TSCC, which may be associated with the activation of immune cells and immune escape of tumor cells. Therefore, in the present study, the presence of Treg and Th17 cells in the peripheral blood of patients with TSCC and their related cytokines was measured. The distribution characteristics of Treg 
and Th17 cells in the TME were also examined to provide novel insight into the development of treatments for clinical immune-targeting TSCC therapies.

\section{Materials and methods}

Patients. A total of 40 patients with TSCC who were admitted to The Department of Oral and Maxillofacial Surgery, Second Affiliated Hospital of Jinzhou Medical University (Liaoning, China) between January 2017 and June 2018 were used in the present study. The cohort consisted of 24 males and 16 females, aged 40-76 years old, with a median age of 54 years. The inclusion criteria were that all patients were diagnosed with TSCC by pathology and no radiation therapy or chemotherapy was performed prior to biopsy. Patients with one or more of the following conditions were excluded: i) Infectious disease; ii) acute cardiovascular and cerebrovascular diseases; iii) rheumatic disease; iv) diabetes; and v) other tumors. The present study was approved by The Ethical Committee of Jinzhou Medical University (Liaoning, China). Informed consent was obtained from all patients included in the study. In addition, 16 healthy individuals with no statistical difference in age and sex were used as the control group. All the participants were informed and blood samples of patients were collected prior to clinical treatment.

Sample collection. A total of $3 \mathrm{ml}$ venous blood of each participant was collected and heparin sodium $(10 \mathrm{mg} / \mathrm{ml}$, Sigma-Aldrich; Merck KGaA) was used as an anticoagulant. Half of each blood sample was centrifuged ( $200 \mathrm{x} \mathrm{g} ; 10 \mathrm{~min}$; room temperature) to prepare serum samples with the remainder used to prepare peripheral blood mononuclear cells (PBMCs). All blood samples were processed within $6 \mathrm{~h}$ of collection.

Hematoxylin and eosin $(H \& E)$ staining. TSCC tissues were fixed ( $>24 \mathrm{~h}$ at room temperature) in $4 \%$ paraformaldehyde and embedded in paraffin. Paraffin-embedded samples were cut into $4 \mu \mathrm{m}$ sections and resected specimens were dewaxed in xylene, rehydrated, washed in distilled water and then stained with hematoxylin and eosin at room temperature for $5 \mathrm{~min}$. Pathological alterations of myocardial tissue were observed under a light microscope (magnification, x200).

Preparation of PBMCs. PBMCs were isolated from the blood samples of patients with TSCC and healthy controls using lysing buffer (BD Biosciences) according to the manufacturer's protocol. Briefly, $3 \mathrm{ml} 1 \mathrm{x}$ lysing solution was added to $3 \mathrm{ml}$ venous blood, samples were incubated on ice for $5 \mathrm{~min}$, centrifuged at $200 \mathrm{xg}$ for $5 \mathrm{~min}$ at room temperature and then, the supernatant was carefully aspirated. The PBMCs were resuspended in RPMI-1640 medium (HyClone; GE Healthcare Life Sciences) and counted with the density of cells adjusted to $1 \times 10^{6}$ cells $/ \mathrm{ml}$ for cell culture or flow cytometry analysis.

Flow cytometric analysis of cluster of differentiation (CD)4+/CD25+/forkhead box protein 3 (Foxp3)+ Treg cells. The PBMCs were resuspended in PBS. For surface staining, fluorescein isothiocyanate-conjugated anti CD4 antibody (cat. no. 555346; BD Biosciences) and
Table I. Characteristic features of patients included in the present study.

\begin{tabular}{|c|c|c|}
\hline Characteristics & $\begin{array}{c}\text { Patients with } \\
\text { tongue squamous cell } \\
\text { carcinoma }\end{array}$ & Controls \\
\hline \multicolumn{3}{|l|}{ Age, year } \\
\hline Range & $38-76$ & $35-71$ \\
\hline Mean \pm SD & $57 \pm 9.25$ & $59 \pm 11.38$ \\
\hline Smoking & 21 & 20 \\
\hline Non-smoking & 19 & 20 \\
\hline Drinking & 15 & 20 \\
\hline Non-drinking & 25 & 20 \\
\hline Local stimulation & 5 & - \\
\hline $\begin{array}{l}\text { Residual roots and } \\
\text { crowns of teeth }\end{array}$ & 3 & \\
\hline Bad prosthesis & 2 & \\
\hline Tumor location & & - \\
\hline Lingual margin & 26 & \\
\hline Lingual root & 8 & \\
\hline Ventral of tongue & 6 & \\
\hline Tumor size & & - \\
\hline $\mathrm{T} 1$ & 4 & \\
\hline $\mathrm{T} 2$ & 21 & \\
\hline $\mathrm{T} 3$ & 10 & \\
\hline $\mathrm{T} 4$ & 5 & \\
\hline Lymph node involvement & & - \\
\hline No & 23 & \\
\hline $\mathrm{N}+$ & 17 & \\
\hline Pathological classification & & - \\
\hline Squamous cell carcinoma & 40 & \\
\hline Histological classification & & - \\
\hline Well differentiated & 11 & \\
\hline Moderately differentiated & 24 & \\
\hline Poorly differentiated & 5 & \\
\hline Clinical stage & & - \\
\hline I & 4 & \\
\hline II & 12 & \\
\hline III & 17 & \\
\hline IV & 7 & \\
\hline
\end{tabular}

allophycocyanin-conjugated anti CD25 antibodies (cat. no. 555434; BD Biosciences) were used. The cells were incubated at room temperature for $20 \mathrm{~min}$ protected from light, washed with 1X PBS twice then fixed and permeabilized for $40 \mathrm{~min}$ at room temperature using a fixation/permeabilization kit (cat. no. 555028, BD Biosciences) according to the manufacturer's protocol. After fixation and permeabilization, a phycoerythrin (PE)-conjugated anti-Foxp3 antibody (cat. no. 72-5774-40; eBioscience; Thermo Fisher Scientific, Inc.) was added. The cells were incubated at room temperature for $45 \mathrm{~min}$ protected from light then washed twice. After discarding the supernatant, cells were resuspended in $300 \mu \mathrm{l}$ 

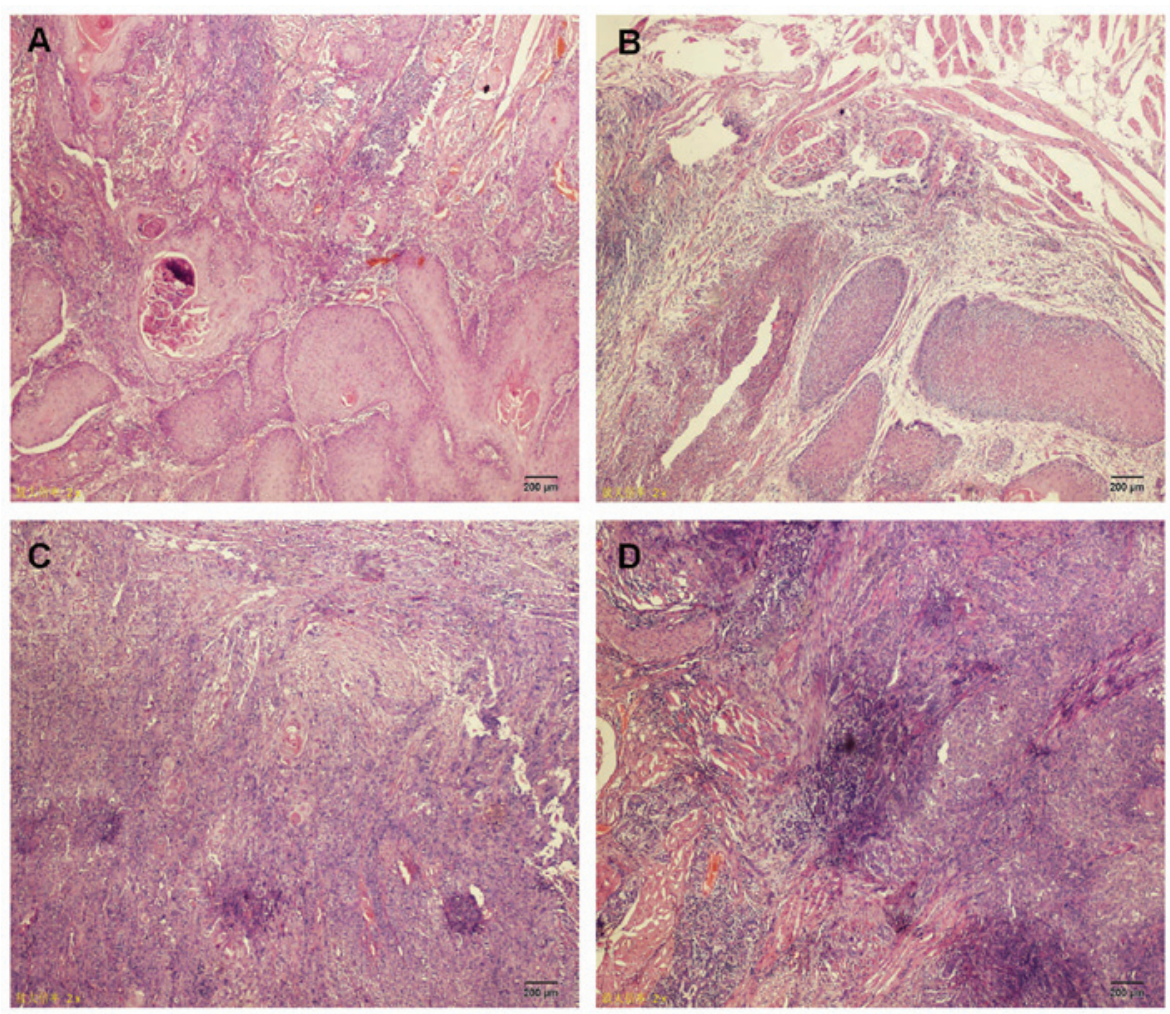

Figure 1. Hematoxylin and eosin staining in patients with TSCC. (A and B) Well differentiated TSCC. (C) Moderately differentiated TSCC. (D) Poorly differentiated TSCC. Magnification, x200. TSCC, tongue squamous cell carcinoma.

PBS for analysis using a flow cytometer. The results were analyzed using FlowJo version 10.1 (Tree Star, Inc.).

Cell culture. PBMCs were resuspended to a density of $2 \times 10^{6}$ cells $/ \mathrm{ml}$, supplemented with $10 \%$ heat-inactivated fetal bovine serum (HyClone; GE Healthcare Life Sciences) and treated with phorbol-12-myristate-13-acetate (PMA; $10 \mathrm{ng} / \mathrm{ml}$; Sigma-Aldrich; Merck KGaA), ionomycin $(0.5 \mu \mathrm{g} / \mathrm{ml}$; Sigma-Aldrich; Merck KGaA), and Brefedin A $\left(1 \mu \mathrm{l} / \mathrm{ml}\right.$; BD Biosciences) in a $37^{\circ} \mathrm{C}, 5 \% \mathrm{CO}_{2}$ incubator for $5 \mathrm{~h}$. The cultured cells were harvested and stained for surface markers and intracellular IL-17a.

Flow cytometric analysis of CD4+IL-17a+ Th17 cells. Surface staining was described as above. The cells were washed once with PBS then fixed and permeabilized for $40 \mathrm{~min}$ at room temperature using a fixation/permeabilization kit (cat. no. 555028; BD Biosciences) following the manufacturer's protocols. Following fixation and permeabilization, anti-IL-17a PE (cat. no. 560436; BD Biosciences) was added. The cells were incubated at room temperature for $45 \mathrm{~min}$ protected from light then washed twice. After discarding the supernatant, cells were resuspended in $300 \mu \mathrm{l}$ PBS for flow cytometry. Data analysis was performed using FlowJo software (version 10.6.0; FlowJo LLC).

Reverse transcription-quantitative PCR (RT-qPCR). PBMCs were collected and total RNA was extracted with TRIzol ${ }^{\circledR}$ reagent (Invitrogen; Thermo Fisher Scientific, Inc.). cDNA was reverse transcribed from total RNA using a RT kit (cat. no. K1622; Thermo Fisher Scientific, Inc.), according to the manufacturers' protocol. qPCR was performed using SYBR Select Master mix (Thermo Fisher Scientific, Inc.), according to the manufacturer's protocol. The primer sequences were as follows: Foxp3 forward, 5'-GCAGCTCTCAACGGTGGA T-3' and reverse, 5'-GGGATTTGGGAAGGTGCAGA-3'; RAR-related orphan receptor- $\gamma(\mathrm{ROR} \gamma \mathrm{t})$ forward, 5'-GCC AAGGCTCAGTCATGAGA-3' and reverse, 5'-CCTCACAGG TGATAACCCCG-3'; and GAPDH forward, 5'-TGTTGCCAT CAATGACCCCTT-3' and reverse, 5'-CTCCACGACGTACTC AGCG-3'. The PCR thermocycling conditions were $50^{\circ} \mathrm{C}$ for $2 \mathrm{~min}, 95^{\circ} \mathrm{C}$ for $2 \mathrm{~min}, 95^{\circ} \mathrm{C}$ for $15 \mathrm{sec}$, and $60^{\circ} \mathrm{C}$ for $1 \mathrm{~min}$, for a total of 40 cycles. The $2^{-\Delta \Delta C q}$ method was used to calculate the relative gene expression (12).

Cytometric bead array (CBA). Serum samples were isolated from the blood of patients with TSCC and healthy controls via centrifugation at $450 \mathrm{x}$ g for $10 \mathrm{~min}$ at room temperature. IL-10 and IL-17a levels were detected using the $\mathrm{BD}^{\mathrm{TM}} \mathrm{CBA}$ Human Th1/Th2/Th17 Cytokine kit (cat. no. 560484; BD Biosciences) according to the manufacturer's protocol. IL-10 and IL-17a levels were analyzed using FCAP Array v3.0 software (BD Biosciences).

Statistical analysis. All data are presented as the mean \pm standard deviation. Statistical analysis was performed using GraphPad Prism 6.0 (GraphPad Software, Inc.). The data was compared using unpaired 2-tailed Student's t-test. One-way analysis of variance followed by Kruskal-Wallis test was used to compare differences amongst multiple groups. $\mathrm{P}<0.05$ was considered to indicate statistical significance. Experiments were performed in triplicate. 

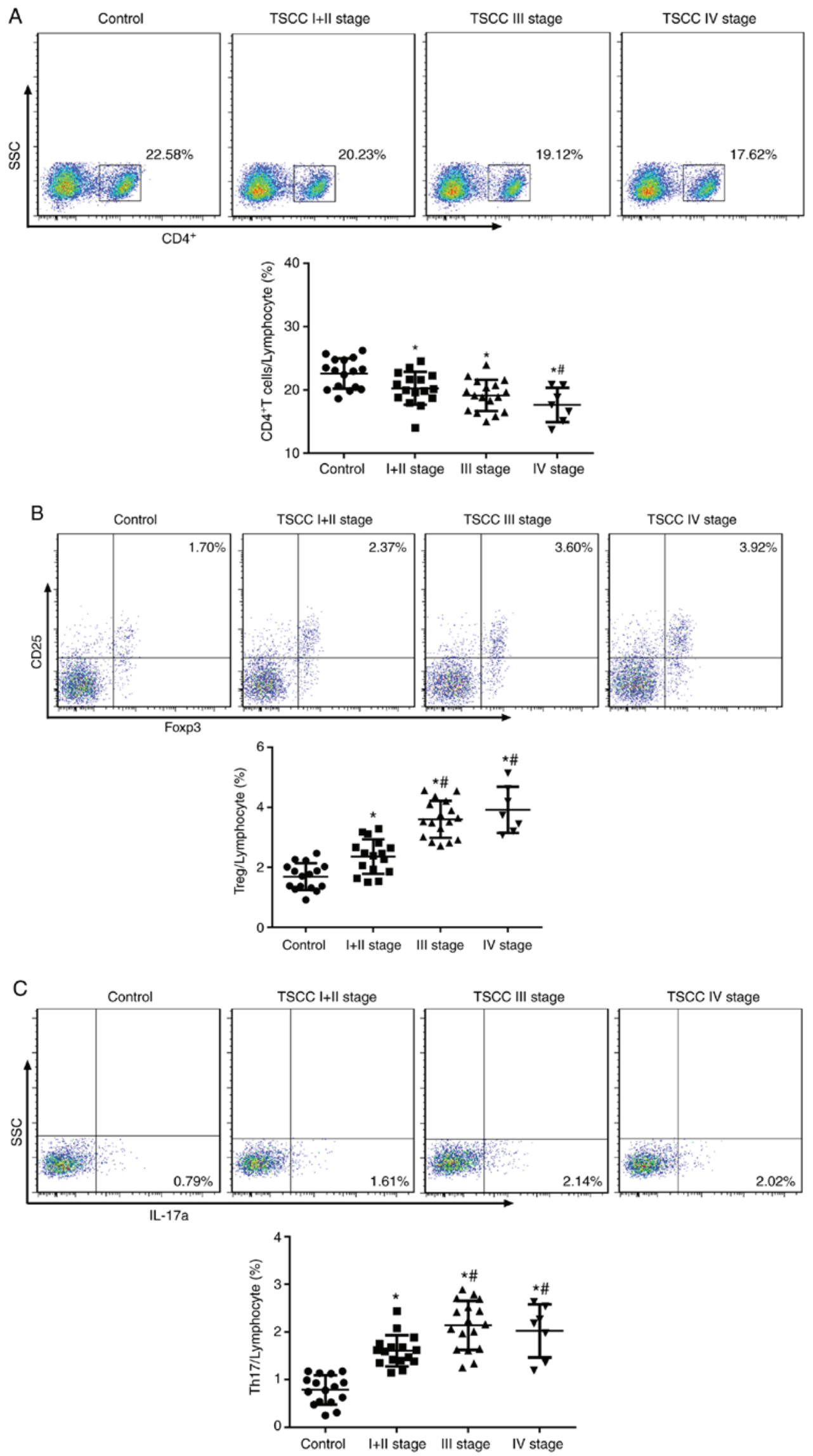

Figure 2. Treg and Th17 cell counts in patients with TSCC. Gating criteria was used to define the CD4+ T cell population and the CD4+/CD25+/Foxp3+ Treg cells were identified. Different cell subsets were distinguished according to different cell labels: Treg cells, CD4+/CD25+/Foxp3+; and Th17 cells, CD4+/L-17a+ cells. (A) Flow cytometry plots and quantification of CD4+T cells, (B) CD4+/CD25+/Foxp3+ Treg cells and (C) CD4+/IL-17a+ cells. Each point represents a patient with TSCC or a healthy person. ${ }^{*} \mathrm{P}<0.05$ vs. control group; ${ }^{*} \mathrm{P}<0.05$ vs. TSCC stage I + II. TSCC, tongue squamous cell carcinoma; Treg, regulatory T helper cell; Th17, T helper cell 17; CD, cluster of differentiation; Foxp3, forkhead box protein 3; SSC, side scatter. 

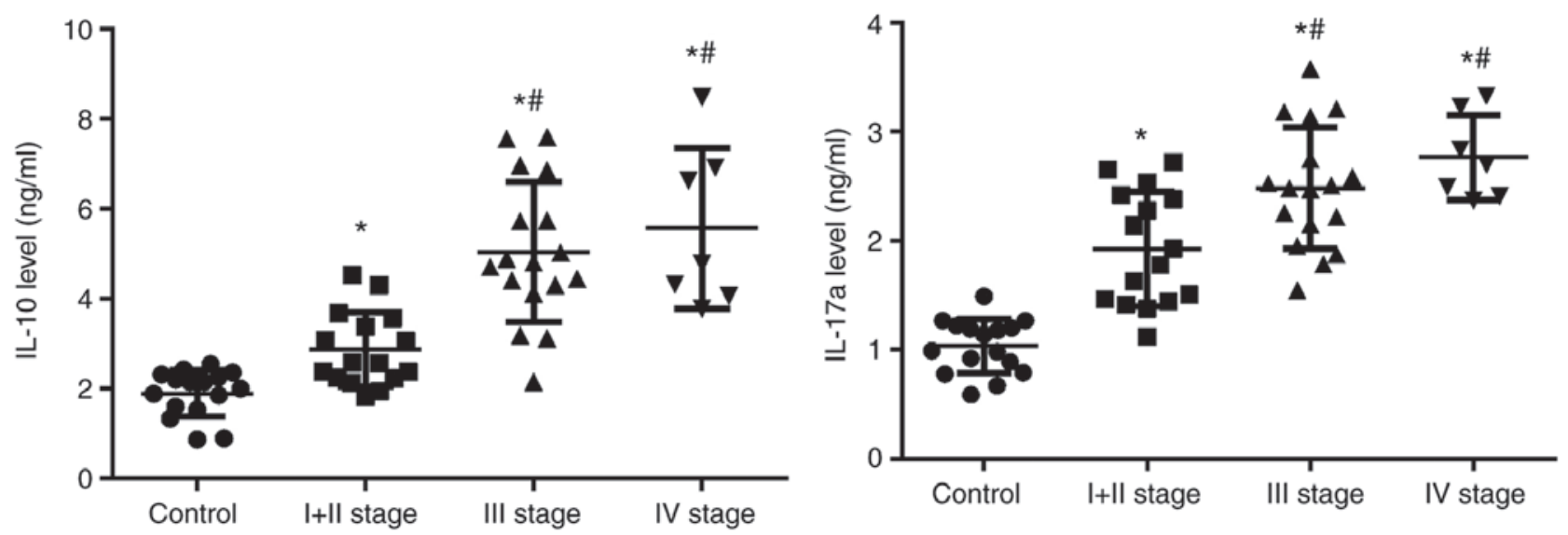

Figure 3. IL-10 and IL-17a levels in the plasma of patients with TSCC. IL-10 and IL-17a were detected using cytometric bead array. Each point represents a patient with TSCC or a healthy person. ${ }^{~} \mathrm{P}<0.05$ vs. control group; ${ }^{~} \mathrm{P}<0.05$ vs. TSCC stage I + II. TSCC, tongue squamous cell carcinoma; IL, interleukin.
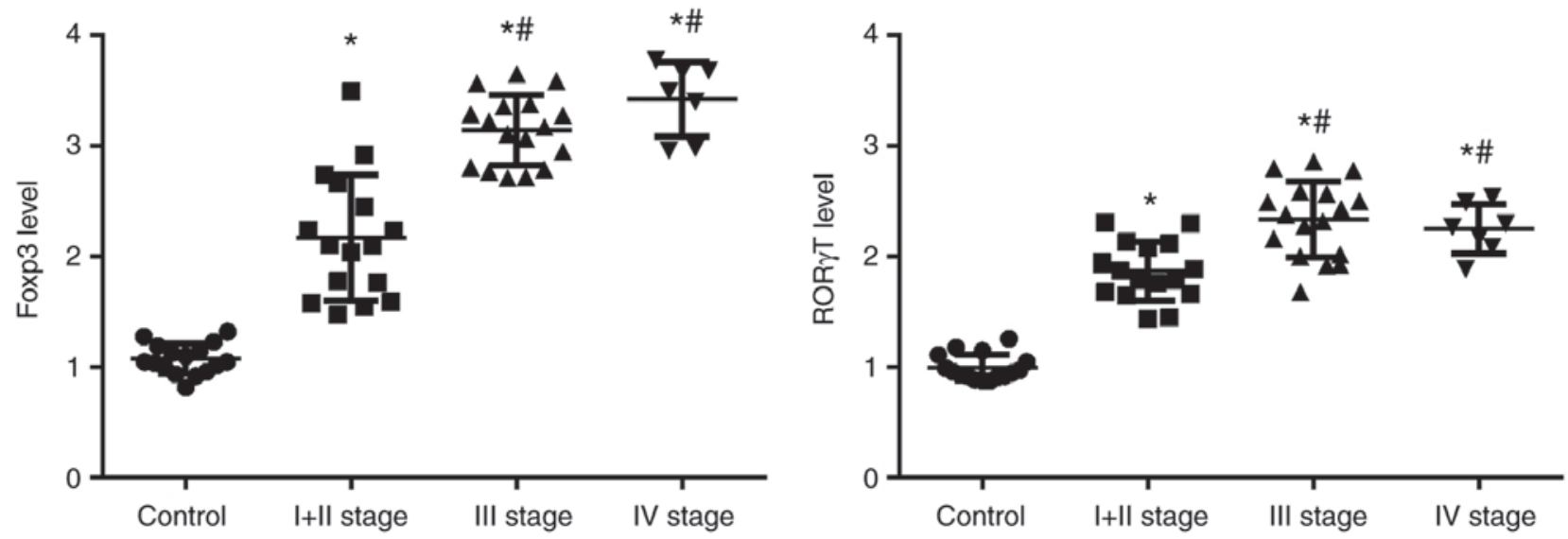

Figure 4. Foxp3 and ROR $\gamma$ t levels in peripheral blood mononuclear cells of TSCC patients. Each point represents a patient with TSCC or a healthy person. "P $<0.05$ vs. control group; ${ }^{\#} \mathrm{P}<0.05$ vs. TSCC stage I + II. TSCC, tongue squamous cell carcinoma; Foxp3, forkhead box protein 3; ROR $\gamma$ t, RAR-related orphan receptor- $\gamma$.

\section{Results}

Clinical characteristics of patients with TSCC. Clinical characteristics of patients with TSCC are presented in Table I. According to the Tumor-Node-Metastasis (TNM) classification for TSCC [Union for International Cancer Control, UICC 2010, 7th Edition (13)], the patients were divided into four stages: Stage I $(n=4)$; stage II $(n=12)$; stage III $(n=17)$; and stage IV $(n=7)$. H\&E staining demonstrated that all patients had squamous cell carcinoma (Fig. 1).

CD4+/CD25+/Foxp3+ Treg cells and CD4+/IL-17a+Th17 cells in patients with TSCC. To investigate the function of the immune system in patients with TSCC, CD4+ T cells were detected using flow cytometry. The results showed that the expression of CD4+T cells decreased in all TSCC patients. The capacity of patients to express CD4+T cells was relatively low (Fig. 2A). The percentage of Treg cells in the peripheral blood of patients with TSCC was significantly increased compared with the control group (control, $1.70 \pm 0.44 \%$; stage I+II, $2.37 \pm 0.58 \%$; stage III, $3.64 \pm 0.61 \%$; and stage IV, $3.92 \pm 0.77 \%$; Fig. 2B). The patients with advanced staged cancer (III or IV) exhibited significantly increased expression compared with patients with early stage cancer (I + II). The percentage of Th17 cells in the peripheral blood of patients with TSCC was significantly increased compared with the control. The percentage of Th17 cells increased significantly in with stage of cancer (Fig. 2C). These results indicated that $\mathrm{T}$ cells and Th17 cells affected the development of TSCC.

IL-10 and IL-17a expression levels increase in patients with TSCC. Tregs primarily exert immunoregulatory effects by producing IL-10 and Th17 cells primarily serve a role by secreting IL-17. IL-10 and IL-17a were detected in the peripheral blood of patients with TSCC using CBA. The results demonstrated that IL-10 (control 1.90 $\pm 0.52 \%$; stage I + II, $2.87 \pm 0.82 \%$; stage III, $5.04 \pm 1.53 \%$; and stage IV, $5.57 \pm 1.78 \%$ ) and IL-17a (control $1.04 \pm 0.25 \%$; stage I + II, $1.93 \pm 0.52 \%$; stage III, $2.48 \pm 0.56 \%$; and stage IV, $2.77 \pm 0.29 \%$ ) in peripheral blood of patients with TSCC was significantly higher compared with the control (Fig. 3), Patients with advanced stage cancer (III or IV) exhibited significantly increased expression compared with patients with early stage cancer (I + II). These results suggested that, in line with the alterations in Treg and Th17 cells, the serum levels of IL-10 and IL-17 were increased gradually in patients with TSCC. 
Foxp3 and ROR $\gamma$ t levels increase in patients with TSCC. Foxp3 and ROR $\gamma \mathrm{t}$ are transcription factors in Treg and Th17 cells, respectively. The levels of Foxp3 and ROR $\gamma$ t in PBMCs from patients with TSCC were detected using RT-qPCR. The results demonstrated that the levels of Foxp3 (control 1.07 $\pm 0.13 \%$; stage I + II, $2.17 \pm 0.57 \%$; stage III, $3.14 \pm 0.31 \%$; and stage IV, $3.42 \pm 0.33 \%$ ) and ROR $\gamma \mathrm{t}$ (control $0.99 \pm 0.12 \%$; stage I + II, $1.87 \pm 0.27 \%$; stage III, $2.34 \pm 0.34 \%$; and stage IV, $2.25 \pm 0.23 \%$ ) in peripheral blood of patients with TSCC were significantly higher compared with the control (Fig. 4). Expression in patients with advanced stages of TSCC (III or IV) was significantly higher compared with patients with early stage TSCC (I + II). These results were consistent with the changes in Treg cells and Th17 cells. These results further demonstrated that Treg cells and Th17 cells affected the development of TSCC.

\section{Discussion}

The immune status of cancer patients is closely associated with the occurrence of cancer (14). Traditionally, it is considered that the immune response and immune surveillance can inhibit the occurrence of tumors but increasing evidence has demonstrated that chronic inflammation caused by the immune response may promote the occurrence and development of tumors (14). As an important immune cell in the tumor microenvironment, Th17 cells have strong pro-inflammatory functions (9). Conversely, Tregs exhibit strong immunosuppressive functions (10). Tumor cells can directly induce Treg cells to produce chemokines, creating a favorable environment for tumor growth and inhibiting the immune response. Therefore, Treg cells can be used as an indicator of disease progression and prognosis and also as a therapeutic index for TSCC (15). The Treg/Th17 cell imbalance is associated with the development of many diseases and tumors (16). Increasing Treg cell count and IL-10 levels may inhibit other effector T cells, interfering with the Treg/Th17 balance and leading to disease progression (15). In the present study, the Treg and Th17 cell counts were measured in the peripheral blood of patients with TSCC, with the findings potentially providing insight into understanding the immune response in patients with TSCC.

Tregs are a subset of cells that control the body's autoimmune response. Numerous studies have determined that Treg serve an important role in tumor immunity. Tregs can inhibit the anti-tumor immune response and promote the development of an immunosuppressive TME, thus promoting immune escape and cancer progression (17-19). Rasku et al (20) identified that transient Treg depletion induces regression of metastatic lesions in advanced stage melanoma patients. Ladoire et al (21) found that Treg depletion prior to treatment is associated with an anti-tumor immune response and improved clinical outcomes in breast cancer patients undergoing tumor resection and radiotherapy. The most prominent transcription factor in Tregs is Foxp3. Recent studies have identified that Foxp3 is expressed in TSCC cell lines $(22,23)$. In the present study, the results demonstrated that the percentage of Treg cells in the peripheral blood of patients with TSCC increased significantly. Taken together, these findings may explain immune escape and proliferation of cancer cells. However, further experiments are required to verify this proposed mechanism.
Th17 cells are a group of cells different from Th1 and Th2 cell subsets. Th17 cells produce IL-17 to promote and stabilize the transcription of other inflammatory factors such as tumor necrosis factor- $\alpha$ to promote tissue inflammation $(24,25)$. Wang et al $(26)$ determined that the growth rate of melanoma and bladder cancer decreases in IL-17 deficient mice. The results suggest that Th17 cells can promote the growth of tumors. De Simone et al (27) found that Th17-type cytokines activate signal transducer and activator of transcription 3 and NF- $\mathrm{KB}$ to promote colorectal cancer cell growth. In the present study compared with the control, the percentage of Th17 cells in the peripheral blood of patients with TSCC was significantly increased with the level of IL-17 produced by Th17 and the expression of ROR $\gamma \mathrm{t}$, a specific transcription factor of Th17 cells also significantly increased. These results indicated that Th17 cells contributed to the proliferation of tumor cells. Treg cell transcription factor Foxp3 can bind to ROR $\gamma \mathrm{t}$, thus inhibiting the activity of ROR $\gamma \mathrm{t}$. ROR $\gamma \mathrm{t}$ is a specific transcription factor of Th17 cells and the two transcription factors are mutually inhibited $(28,29)$. Under normal circumstances, Treg/Th17 can maintain balance (30). However, when the balance of Treg/Th17 cells is lost, it may result in the promotion and development of tumors. The results of the present study demonstrated that Treg/Th17 cell counts and IL-10/IL-17 levels increased, providing an additional mode of analysis to improve prediction of the prognosis of patients with TSCC.

In conclusion, the present study determined that the percentage of Treg/Th17 cells and IL-10/IL-17 levels increased significantly in patients with TSCC. The immune balance of Treg and Th17 cells was lost, possibly resulting in rapid proliferation of tumor cells. The detection of Treg and Th17 cells may be useful in diagnosing TSCC and predicting its pathogenesis. The results of the present study suggested that adoptive immunotherapy may be developed through modulation of Treg and Th17 populations in the future.

\section{Acknowledgements}

Not applicable.

\section{Funding}

The present study was funded by The Nature Science Foundation of Liaoning Province (grant no. 2015020326).

\section{Availability of data and materials}

The datasets generated and/or analyzed during the present study are available from the corresponding author on reasonable request.

\section{Authors' contributions}

CFL and ZXX conceived and designed the study. CFL drafted the manuscript. Flow cytometry was completed by ZT. Cell culture was completed by JYT and ZT. Reverese transcription-quantitative PCR was performed by JYT. Data analysis was performed by ZXX. All authors read and approved the final version. 


\section{Ethics approval and consent to participate}

The present study was approved by the Ethical Committee of Jinzhou Medical University (Liaoning, China; approval no. JZH2016052). Informed consent was obtained from all patients included in the study.

\section{Patient consent for publication}

Not applicable.

\section{Competing interests}

The authors declare that they have no competing interests.

\section{References}

1. Yu X and Li Z: MicroRNA expression and its implications for diagnosis and therapy of tongue squamous cell carcinoma. J Cell Mol Med 20: 10-16, 2016.

2. Finotello F andEduati F: Multi-omics profiling of the tumor microenvironment: paving the way to precision immuno-oncology. Front Oncol 8: 430, 2018.

3. Kim J and Bae JS: Tumor-associated macrophages and neutrophils in tumor microenvironment. Mediators Inflamm 2016 6058147, 2016.

4. Jiang W, Chan CK, Weissman IL, Kim BYS and Hahn SM: Immune priming of the tumor microenvironment by radiation. Trends Cancer 2: 638-645, 2016.

5. Sahoo SS, Zhang XD, Hondermarck H and Tanwar PS: The emerging role of the microenvironment in endometrial cancer. Cancers (Basel) 10: pii: E408, 2018.

6. Steven A and Seliger B: The role of immune escape and immune cell infiltration in breast cancer. Breast Care (Basel) 13: 16-21, 2018.

7. Terry S, Savagner P, Ortiz-Cuaran S, Mahjoubi L, Saintigny P, Thiery JP and Chouaib S: New insights into the role of EMT in tumor immune escape. Mol Oncol 11: 824-846, 2017.

8. Spranger S: Mechanisms of tumor escape in the context of the T-cell-inflamed and the non-T-cell-inflamed tumor microenvironment. Int Immunol 28: 383-391, 2016.

9. Barbi J, Pardoll D and Pan F: Treg functional stability and its responsiveness to the microenvironment. Immunol Rev 259: 115-139, 2014

10. Guéry L and Hugues S: Th17 Cell plasticity and functions in cancer immunity. Biomed Res Int 2015: 314620, 2015.

11. Zhou X, Su YX, Lao XM, Liang YJ and Liao GQ: CD19(+) IL-10(+) regulatory $B$ cells affect survival of tongue squamous cell carcinoma patients and induce resting CD4(+) $\mathrm{T}$ cells to CD4(+)Foxp3(+) regulatory T cells. Oral Oncol 53: 27-35, 2016.

12. Livak KJ and Schmittgen TD: Analysis of relative gene expression data using real-time quantitative PCR and the 2(-Delta Delta C(T)) method. Methods 25: 402-408, 2001.

13. Sobin LH, Gospodarowicz MK and Wittekind $\mathrm{CH}$ (eds): UICC International Union Against Cancer TNM Classification of Malignant Tumors. 7th edition. West Sussex, United Kingdom, Wiley-Blackwell, 2009.

14. Zamarron BF and Chen $\mathrm{W}$ : Dual roles of immune cells and their factors in cancer development and progression. Int J Biol Sci 7: 651-658, 2011.
15. Jadidi-Niaragh F, Ghalamfarsa G, Memarian A, Asgarian-Omran H, Razavi SM, Sarrafnejad A and Shokri F: Downregulation of IL-17-producing T cells is associated with regulatory $\mathrm{T}$ cell expansion and disease progression in chronic lymphocytic leukemia. Tumour Biol 34: 929-940, 2013.

16. Duan MC, Han W, Jin PW, Wei YP, Wei Q, Zhang LM and Li JC: Disturbed Th17/treg balance in patients with non-small cell lung cancer. Inflammation 38: 2156-2165, 2015.

17. Chaudhary B and Elkord E: Regulatory $\mathrm{T}$ cells in the tumor microenvironment and cancer progression: Role and therapeutic targeting. Vaccines (Basel) 4: pii: E28, 2016.

18. Tanaka A and Sakaguchi S: Regulatory T cells in cancer immunotherapy. Cell Res 27: 109-118, 2017.

19. Elkord E,Alcantar-Orozco EM, Dovedi SJ, Tran DQ, Hawkins RE and Gilham DE: T regulatory cells in cancer: Recent advances and therapeutic potential. Expert Opin Biol Ther 10: 1573-1586, 2010.

20. Rasku MA, Clem AL, Telang S, Taft B, Gettings K, Gragg H, Cramer D, Lear SC, McMasters KM, Miller DM and Chesney J: Transient T cell depletion causes regression of melanoma metastases. J Transl Med 6: 12, 2008.

21. Ladoire S, Arnould L, Apetoh L, Coudert B, Martin F, Chauffert B, Fumoleau $\mathrm{P}$ and Ghiringhelli F: Pathologic complete response to neoadjuvant chemotherapy of breast carcinoma is associated with the disappearance of tumor-infiltrating foxp3+ regulatory $\mathrm{T}$ cells. Clin Cancer Res 14: 2413-2420, 2008.

22. Liang YJ, Lao XM, Liang LZ and Liao GQ: Genome-wide analysis of cancer cell-derived Foxp3 target genes in human tongue squamous cell carcinoma cells. Int J Oncol 46: 1935-1943, 2015.

23. Li K, Huang SH, Lao XM, Yang L, Liao GQ and Liang YJ: Interaction of cancer cell-derived Foxp3 and tumor microenvironment in human tongue squamous cell carcinoma. Exp Cell Res 370: 643-652, 2018.

24. Zhu S and Qian Y: IL-17/IL-17 receptor system in autoimmune disease: Mechanisms and therapeutic potential. Clin Sci (Lond) 122: 487-511, 2012.

25. Chen X and Oppenheim JJ: Th17 cells and Tregs: Unlikely allies. J Leukoc Biol 95: 723-731, 2014.

26. Wang L, Yi T, Kortylewski M, Pardoll DM, Zeng D and Yu H: IL-17 can promote tumor growth through an IL-6-Stat3 signaling pathway. J Exp Med 206: 1457-1464, 2009.

27. De Simone V, Franzè E, Ronchetti G, Colantoni A, Fantini MC, Di Fusco D, Sica GS, Sileri P, MacDonald TT, Pallone F, et al: Th17-type cytokines, IL-6 and TNF- $\alpha$ synergistically activate STAT3 and NF-kB to promote colorectal cancer cell growth. Oncogene 34: 3493-3503, 2015.

28. Yang F, Wang D, Li Y, Sang L, Zhu J, Wang J, Wei B, Lu C and Sun X: Th1/Th2 balance and Th17/treg-mediated immunity in relation to murine resistance to dextran sulfate-induced colitis. J Immunol Res 2017: 7047201, 2017.

29. Sun J, Li L, Li L, Ding L, Liu X, Chen X, Zhang J, Qi X, Du J and Huang Z: Metallothionein-1 suppresses rheumatoid arthritis pathogenesis by shifting the Th17/Treg balance. Eur J Immunol 48: 1550-1562, 2018.

30. Zhao L, Yang J, Wang HP and Liu RY: Imbalance in the Th17/Treg and cytokine environment in peripheral blood of patients with adenocarcinoma and squamous cell carcinoma. Med Oncol 30: 461, 2013.

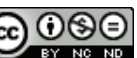

This work is licensed under a Creative Commons Attribution-NonCommercial-NoDerivatives 4.0 International (CC BY-NC-ND 4.0) License. 